\title{
TRAJETÓRIAS DE VIDA, CONDIÇÕES DE TRABALHO E DE SAÚDE- DOENÇA DE FEIRANTES HOMENS
}

\author{
Weslly Bernardes de Oliveira ${ }^{1}$; Maria Geralda Gomes Aguiar ${ }^{\mathbf{2}}$ \\ 1. Bolsista PROIC/UEFS, Graduando em Enfermagem, Universidade Estadual de Feira de Santana, e-mail: \\ wboenfuefs@gemail.com \\ 2. Orientador, Departamento de nome, Universidade Estadual de Feira de Santana, e-mail: geaguiar@uefs.br
}

PALAVRAS-CHAVE: condições de trabalho; processo saúde-doença; trabalhadores informais.

\section{INTRODUÇÃO}

$\mathrm{O}$ ato de trabalhar é um dos fatores que tem maior relação com as condições de vida, de saúde e qualidade de vida do homem, particularmente, quando se trata do trabalho informal, como é o caso da atividade do feirante, na qual o trabalhador está exposto, segundo Almeida e Pena (2011) a “[...] variações climáticas, longa jornada de trabalho, ausência de dispositivos e mecanismos básicos de proteção, entre outros fatores de risco para a saúde", devido às próprias características da atividade laboral que desempenha.

Estudo realizado com feirantes de Feira de Santana - BA por Carvalho e outros (2017) sobre as características sociodemográficas e os fatores de risco à saúde destes trabalhadores, evidenciou que estes labutam diariamente sob condições de trabalho insalubres e exaustivas que os tornam vulneráveis ao aparecimento de doenças e complicações. São destacadas a precariedade do ambiente, cargas horárias extensas e ausência de horários definidos para alimentação, descanso e lazer, que repercutem de forma negativa na saúde dos feirantes. O fato dos homens serem os responsáveis pelo sustendo de suas famílias, reflete na forma como cuidam de sua saúde, tendo em vista que a extensa carga horária de trabalho dificulta a ida aos serviços de atenção à saúde Cavalcanti et al (2014).

É inegável a preocupação masculina com a atividade laboral, a qual tem um lugar destacado, sobretudo entre indivíduos de baixa condição social, o que reforça o papel historicamente atribuído ao homem de ser responsável pelo sustento da família (BRASIL, 2008). A forma como o homem compreende seu processo-saúde-doença, muitas vezes, condiz com uma imagem forte e viril historicamente construída, ao passo que a identidade social dos homens elaborada nas relações sociais constrói não só, modos de conceber o corpo, a saúde e a doença, mas, igualmente, produzem serviços de saúde baseados em modelos ideais de masculino e feminino Machin et al (2011).

Assim, este estudo se justifica tendo em vista que a análise das trajetórias de vida se mostra importante por valorizar a escuta dos atores sociais envolvidos, e por permitir apreender como se dá a inserção dos feirantes homens no mercado informal, estabelecendo relações entre as condições de trabalho nas feiras livres e os modos como estes trabalhadores percebem seu processo-saúde-doença.

Objetivou-se analisar as inter-relações das trajetórias de vida com as condições de trabalho e de saúde-doença de feirantes homens que atuam na feira livre do Tomba em Feira de Santana - BA, bem como, conhecer a trajetória de vida dos feirantes e os modos de inserção na atividade laboral e descrever a percepção de feirantes homens sobre as suas condições de trabalho e saúde-doença 


\section{METODOLOGIA}

Estudo de abordagem qualitativa, do tipo exploratório, na perspectiva narrativa. A pesquisa foi realizada no município de Feira de Santana - BA, foram participantes seis feirantes homens a partir dos 18 anos de idade, que estivessem atuando na feira livre do Tomba há pelo menos um ano. O número de feirantes foi definido mediante saturação teórica das respostas, operacionalmente definida como a suspensão de inclusão de novos participantes quando os dados obtidos passam a apresentar, certa redundância ou repetição, não sendo considerado relevante persistir na coleta de dados (FONTANELLA; RICAS; TURATO 2008).

A entrevista narrativa foi utilizada a fim de que o participante, contasse sua história relativa à inserção na atividade de feirante, ao tipo de trabalho que realizava e o contexto em que é desenvolvida. A análise dos dados se apoiou na proposta de Schütze (1992) por entender que esta permitiria uma aproximação com as trajetórias de vida dos feirantes, tendo em vista a compreensão dos relatos do processo de inserção no contexto das feiras livres, de maneira articulada à percepção do seu processo saúde-doença e condições de trabalho. O método é composto por seis passos, partindo inicialmente de uma análise formal do texto, selecionando e ordenando as narrativas que descrevem a sequência dos acontecimentos, sendo, portanto, classificado como material indexado, em seguida resgata-se as argumentações das narrativas, referentes aos componentes não-indexados, como a autodescrição biográfica, descrições abstratas e avaliações gerais. Após isto, parte-se para a comparação constrativa entre as diferentes narrativas, buscando semelhanças a fim de compará-las, por conseguinte os resultados foram descritos e discutidos teoricamente.

Antecedente à entrevista com os participantes, ofertamos o Termo de Consentimento Livre e Esclarecido (TCLE), o qual garantiu os direitos do participante como o sigilo das informações, o anonimato e a liberdade para participarem ou desligarem-se do estudo se assim desejassem, tendo-se como referência os aspectos éticos da pesquisa envolvendo seres humanos, conforme preconizados pela Resolução n ${ }^{\circ}$ 466/2012 do Conselho Nacional de Ética em Pesquisa (CONEP) (BRASIL, 2012).

\section{RESULTADOS E DISCUSSÃO}

Participaram do estudo seis homens feirantes, com idades entre 25 e 79 anos, com uma média de idade 45,83 anos, com relação ao tempo que atuam na feira livre do Tomba a média foi de 17,17 anos de trabalho. Em relação à raça/cor, $50 \%$ se autodeclararam pardos e $50 \%$ pretos, quanto ao estado civil $66,67 \%$ referem ser casados e 33,33\% solteiros. A média de dias trabalhados na semana foi de 5,67 dias, no que diz respeito a carga horária diária de trabalho essa é de 11,83 horas, semanalmente a carga horária ultrapassa as sessenta horas trabalhadas, a média foi de 68,17 horas. O grau de escolaridade variou de ensino fundamental incompleto a ensino médio completo.

Para compreender a trajetória de vida de cada homem feirante, a partir da trasncrição das entrevistas realizadas, ordenamos os acontecimentos mais importantes que levaram estes homens a se inserirem no contexto da feira livre, com base nas narrativas traçamos as "trajetórias de vida" abrangendo os componentes indexados que correspondem ao conteúdo racional, dito de outra forma, como o conteúdo concreto que informa quem faz o que, quando faz, onde e porquê, os componentes não-indexados foram apresentadas como "experiência de trabalho" e "condições de trabalho e saúdedoença" divididos em dimensões argumentativas onde os feirantes expressam suas percepções; nas dimensões descritivas os entrevistados narram as suas opiniões e sentimentos. 
A partir disso, ordenamos as trajetórias individuais de cada homem feirante e as comparamos, o que envidenciou que a inserção deste no conxtexto da feira livre sofre influência da família, sendo o principal motivo, seguido pelo desemprego, tendo em vista a dificuldade destes homens se manterem no mercado formal. Nesse sentido, a trajetória destes é permeada por acontecimentos que versam desde o desemprego, a falta de qualificação para o trabalho formal, mas também à cultura, às heranças e costumes familiares.

Ao narrarem sobre o ambiente e suas condições de trabalho, os entrevistados argumentam que o espaço da feira livre do Tomba deixa a desejar em alguns aspectos, como a falta de cobertura que os projeta do sol e da chuva, sanitários suficientes e higienizados para que possam utilizar com dignidade, aspectos que geram sofrimento e revolta e que, acarretam o surgimento de doenças. Contudo, eles argumentam também que apesar das condições de trabalho, atuar na feira livre envolve um processo de construção e estreitamento dos laços, de boa convivência e de parceria entre os feirantes.

Os feirantes inferem que o excesso de peso que habitualmente carregam para montar e abastecer suas barracas, bem como o estresse, caracterizam suas condições de trabalho, dito de outra forma, o conjunto de atividades que estes trabalhadores desenvolvem, aliado ao ambiente de trabalho ruidoso, estressante e que os expõe as variações climáticas de forma que por vezes chegam a ter prejuízos, traduz as condições em que as suas atividades são desenvolvidas.

\section{CONSIDERAÇÕES FINAIS}

Com a realização deste estudo, foi possível analisarmos as trajetórias individuais dos entrevistados, na tentativa de conhecer e descrever os caminhos por eles trilhados, fazendo com que estes chegassem à feira livre e se tornassem trabalhadores feirantes. As trajétorias de vida dos homens feirantes refletem as marcas de uma sociedade baseada nos ideiais patriarcais e excludentes, cuja cultura de inserção dos homens feirantes no mercado de trabalho se dá geralmente na adolescência, de forma que muitos deles não tiveram a oportunidade de estudar.

A família aparece como peça fundamental no que diz respeito à inserção destes na feira livre, as narrativas versam sobre o papel da família desde aqueles que começaram a trabalhar na infância, ajudando seus pais e fazendo serviços para terceiros na feira, bem como aqueles que almejaram manter-se no mercado formal, contudo com as sucessivas situações de desemprego, instabilidade no trabalho ou até mesmo a falta de segurança em seus ambientes trabalhistas, fizeram com que alguns deles também buscassem na feira livre a sua fonte de sobrevivência, bem como garante que os trabalhadores que exercem suas atividades neste espaço possam se manter.

$\mathrm{Na}$ perspectiva das condições de trabalho vivenciadas no mercado informal, sobretudo na feira livre, as narrativas elucidam que este espaço configura-se como um local onde os trabalhadores exercem atividades com carga horária que excede uma média de 11 horas diárias de trabalho, sem direito a folgas e férias, sob sol e chuva, devido à falta de uma cobertura adequada e que garanta melhores condições para que as atividades laborais sejam desenvolvidas, bem como, a falta de sanitários adequados, exposição ao ruído, o que em conjunto, segundo os entrevistados, geram situações de estresse.

Nesse sentido, tais condições de trabalho geram impactos significativos à saúde, como o surgimento de comorbidades, o sono irregular, o estresse; a impossibilidade de uma higiene adequada das mãos para que eles possam se alimentar, o peso que carregam diariamente para abastecer suas barracas. Assim, podemos inferir que estes 
homens feirantes percebem que o seu processo saúde-doença se dá a partir das situações vivenciadas em seu cotidiano, no exercício das suas atividades num ambiente que não proprociona proteção e conforto. No entanto, a feira livre mostra-se também como um ambiente de sociabilidades, de construção e estreitamento de laços, de parcerias e de encontros. O desenvolvimento deste estudo, possibilitou a compreensão do processo de inserção dos feirantes no contexto da feira livre a partir de seus relatos sobre suas trajetórias de vida, bem como a inter-relação entre o trabalho do feirante e o seu processo saúde-doença, tendo como benefícios a possibilidade de criação de estratégias que visam a promoção e prevenção da saúde no âmbito das feiras livres.

\section{REFERÊNCIAS}

ALMEIDA, M.D.; PENA, P.G.L. Feira livre e risco de contaminação alimentar: estudo de abordagem etnográfica em Santo Amaro, Bahia. Rev Baiana de Saúde Pública, Salvador, v. 35, n. 1, p. 110-127, jan./mar. 2011.

BRASIL. Ministério da Saúde. 2012. Conselho Nacional de Saúde. Resolução 466/12, que aprova as diretrizes e normas regulamentadoras de pesquisa envolvendo seres humanos. Brasília, DF: Ministério da Saúde.

CARVALHO, J.J. et al. Características sociodemográficas, do trabalho e fatores de risco à saúde de trabalhadores feirantes. In: AGUIAR, M. G. G. (Org.). Processo saúde/doença e práticas de cuidado no cotidiano de trabalhadores feirantes Feira de Santana, BA. Feira de Santana, BA: UEFS Editora, 2017. Cap. 4, p. 101-135. (No prelo).

CAVALCANTI J.R.D. et al. Assistência Integral a Saúde do Homem: necessidades, obstáculos e estratégias de enfrentamento. Esc. Anna Nery. 2014, Rio de Janeiro, v. 18, n. 4, p. 628-634.

FONTANELLA, B.J.B.; RICAS,J.; TURATO, E.B. Amostragem por saturação em pesquisas qualitativas em saúde: contribuições teóricas. Cad. Saúde Pública., Rio de Janeiro. v. 24, n. 1. p. 17-27, jan. 2008

MACHIN, R. et al. Concepções de gênero, masculinidade e cuidados em saúde: estudo com profissionais de saúde da atenção primária. Ciênc. saúde coletiva, Rio de Janeiro, v. 16, n. 11, p. 4503-4512, 2011.

SCHÜTZE, F. Pressure and guilt: war experiencias of a young german soldier and their biographical implications. International Sociology, Barcelona, v. 7, n. 2, p. 187-208, 1992.

SOUZA, E. et al. Prospecção socioeconômica em feiras livres: o caso do Complexo do Ver-o Peso, Belém, Pará, Brasil. Disponível em:

<http://www.revistaespacios.com/a17v38n36/a17v38n36p05.pdf>. Acesso em: 30 jun. 2018 . 